\title{
Epicardial left ventricular lead placement for cardiac resynchronization therapy: Optimal pace site selection with pressure-volume loops
}

\author{
A. L. A. J. Dekker, $P h D^{a}$ \\ B. Phelps, $M D^{\mathrm{a}}$ \\ B. Dijkman, MD, PhD \\ T. van Der Nagel ${ }^{\mathrm{a}}$ \\ F. H. van Der Veen, $P h D^{a}$ \\ G. G. Geskes, MD \\ J. G. Maessen, MD, PhD ${ }^{a}$
}

From the Departments of Cardio Thoracic Surgery $^{\mathrm{a}}$ and Cardiology, ${ }^{\mathrm{b}}$ Cardiovascular Research Institute Maastricht, Academic Hospital Maastricht, Maastricht, The Netherlands.

Received for publication Aug 22, 2003; revisions requested Sept 28, 2003; accepted for publication Oct 23, 2004.

Address for reprints: J. G. Maessen, MD, $\mathrm{PhD}$, Department of Cardio Thoracic Surgery, Academic Hospital Maastricht, P. Debyelaan 25, 6229 HX Maastricht, The Netherlands (E-mail: j.maessen@scpc. azm.nl).

J Thorac Cardiovasc Surg 2004;127:1641-7 $0022-5223 / \$ 30.00$

Copyright () 2004 by The American Association for Thoracic Surgery

doi:10.1016/j.jtcvs.2003.10.052
Objectives: Patients in heart failure with left bundle branch block benefit from cardiac resynchronization therapy. Usually the left ventricular pacing lead is placed by coronary sinus catheterization; however, this procedure is not always successful, and patients may be referred for surgical epicardial lead placement. The objective of this study was to develop a method to guide epicardial lead placement in cardiac resynchronization therapy.

Methods: Eleven patients in heart failure who were eligible for cardiac resynchronization therapy were referred for surgery because of failed coronary sinus left ventricular lead implantation. Minithoracotomy or thoracoscopy was performed, and a temporary epicardial electrode was used for biventricular pacing at various sites on the left ventricle. Pressure-volume loops with the conductance catheter were used to select the best site for each individual patient.

Results: Relative to the baseline situation, biventricular pacing with an optimal left ventricular lead position significantly increased stroke volume $(+39 \%, P=.01)$, maximal left ventricular pressure derivative $(+20 \%, P=.02)$, ejection fraction $(+30 \%, P=.007)$, and stroke work $(+66 \%, P=.006)$ and reduced end-systolic volume $(-6 \%, P=.04)$. In contrast, biventricular pacing at a suboptimal site did not significantly change left ventricular function and even worsened it in some cases.

Conclusions: To optimize cardiac resynchronization therapy with epicardial leads, mapping to determine the best pace site is a prerequisite. Pressure-volume loops offer real-time guidance for targeting epicardial lead placement during minimal invasive surgery.

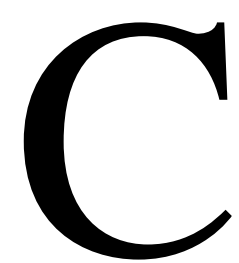

ardiac resynchronization therapy (CRT) reduces symptoms ${ }^{1}$ and mortality $^{2,3}$ among patients with heart failure and left bundle branch block (LBBB). For CRT, a left ventricular pacing electrode is required, which is usually placed by catheterization of the coronary sinus.

Coronary sinus catheterization is associated with a long procedure time, ${ }^{4}$ extensive fluoroscopy, ${ }^{4}$ reported implantation failure in $10 \%$ to $30 \%$ of cases, ${ }^{1,5,6}$ left ventricular lead dislodgment in $6 \%$ to $14 \%$ of initially successfully implanted cases, ${ }^{1,5,6}$ and an increased pacing threshold with time, requiring an intervention in $13 \%$ to $18 \%$ of patients. ${ }^{5,6}$ Perhaps the most important limitation of coronary sinus 
TABLE 1. Patient characteristics

\begin{tabular}{|c|c|c|c|c|c|c|c|c|}
\hline Case & Sex & Age (y) & EF (\%) & NYHA & ORS width & Medications & $\begin{array}{l}\text { Reason for } \\
\text { CTS }\end{array}$ & Cause of CHF \\
\hline 1 & M & 73 & 32 & III & 280 & $\begin{array}{l}\text { Diuretics, BB, } \\
\text { ACE }\end{array}$ & $\begin{array}{l}\text { Lead } \\
\text { dislocation }\end{array}$ & Ischemic \\
\hline 2 & $\mathrm{~F}$ & 50 & 26 & III & 144 & $\begin{array}{l}\text { Diuretics, BB, } \\
\text { ACE }\end{array}$ & $\begin{array}{l}\text { Coronary } \\
\text { sinus } \\
\text { anatomy }\end{array}$ & Ischemic \\
\hline 3 & M & 33 & 13 & III & 184 & $\begin{array}{l}\text { Diuretics, BB, } \\
\text { ACE, } \\
\text { spironolactone }\end{array}$ & $\begin{array}{l}\text { Coronary } \\
\quad \text { sinus } \\
\text { anatomy }\end{array}$ & Nonischemic \\
\hline 4 & M & 73 & 41 & III & 170 & $\begin{array}{l}\text { Diuretics, BB, } \\
\text { ACE, digitalis, } \\
\text { spironolactone }\end{array}$ & $\begin{array}{l}\text { Coronary } \\
\text { sinus } \\
\text { anatomy }\end{array}$ & Ischemic \\
\hline 5 & M & 67 & 26 & III & 152 & $\begin{array}{l}\text { Diuretics, ACE, } \\
\text { spironolactone }\end{array}$ & $\begin{array}{l}\text { Implantation } \\
\text { failure }\end{array}$ & Ischemic \\
\hline 6 & M & 69 & 19 & III & 180 & Diuretics, BB & $\begin{array}{l}\text { Stenosis V } \\
\text { subclavia }\end{array}$ & Ischemic \\
\hline 7 & M & 68 & 22 & $\|-I I I$ & 200 & $\begin{array}{r}\text { Diuretics, ACE, } \\
\text { ARB, digitalis }\end{array}$ & $\begin{array}{l}\text { Stenosis V } \\
\text { subclavia }\end{array}$ & Ischemic \\
\hline 8 & M & 78 & 30 & III & 140 & $\begin{array}{l}\text { Diuretics, BB, } \\
\text { ACE }\end{array}$ & $\begin{array}{c}\text { Occlusion V } \\
\text { subclavia }\end{array}$ & Nonischemic \\
\hline 9 & M & 64 & 21 & III & 180 & $\begin{array}{l}\text { Diuretics, BB, } \\
\text { ACE }\end{array}$ & $\begin{array}{l}\text { Implantation } \\
\text { failure }\end{array}$ & Ischemic \\
\hline 10 & M & 78 & 45 & II-III & 200 & $\mathrm{BB}, \mathrm{ACE}$ & $\begin{array}{c}\text { Occlusion V } \\
\text { subclavia }\end{array}$ & Ischemic \\
\hline 11 & M & 68 & 25 & III & 180 & $\mathrm{BB}, \mathrm{ACE}$ & $\begin{array}{c}\text { Occlusion V } \\
\text { subclavia }\end{array}$ & Ischemic \\
\hline
\end{tabular}

$E F$, Ejection fraction; NYHA, New York Heart Association functional class; $C H F$, congestive heart failure; $M$, male; $B B, \beta$-blocker; $A C E$, angiotensinconverting enzyme inhibitor; $A R B$, angiotensin-renin blocker; $F$, female.

catheterization, however, is that only a limited number of sites can be reached on the left ventricular wall because of the anatomy of the cardiac venous system.

The position of the left ventricular lead is important for the acute hemodynamic effect and the reduction in symptoms with CRT. ${ }^{7-10}$ Recent studies showed that the best position depends on the patient. ${ }^{10,11}$ During surgery various sites can be reached, but no method has been described for pick the right site in the individual patient. In this study we examined a mapping technique with pressure-volume loops for optimal surgical placement of the left ventricular lead for CRT.

\section{Methods \\ Patients}

Eleven patients were referred for surgery because of failed coronary sinus left ventricular lead implantation. Informed consent was obtained in all cases. The reason for failure of implantation and other patient details are given in Table 1. All patients had heart failure with LBBB (QRS duration $>130 \mathrm{~ms}$ ) and a low ejection fraction, meeting the criteria for CRT.

\section{Pressure-Volume Loops}

A conductance catheter (CD Leycom, Zoetermeer, The Netherlands) was placed under fluoroscopic guidance in the left ventricle by catheterization of the right femoral artery. The catheter was connected to a CFL512 conductance console (CD Leycom). Because only relative changes (universal atrioventricular [DDD] vs biventricular pacing) were considered, no calibration was performed during surgery. Off-line, the conductance signals were calibrated to match preoperative ejection fraction and a cardiac output of $4 \mathrm{~L} / \mathrm{min}$. Stroke volume was defined as the volume at maximal left ventricular pressure derivative $\left(\mathrm{dP} / \mathrm{dt}_{\text {max }}\right)$ minus the volume at minimal left ventricular pressure derivative $\left(\mathrm{dP} / \mathrm{dt}_{\min }\right)$. End-diastolic volume was the volume at the R-wave of the internal electrocardiogram of the conductance catheter, and minimal volume was taken as end-systolic volume.

\section{Surgical Procedure}

With general anesthesia and single-lung ventilation with videoassisted thoracoscopic port-access techniques, the pericardium was opened parallel to the left phrenic nerve. The left ventricular free wall was then mapped with a temporary pacemaker electrode in a systematic way. The anterior, anterolateral, lateral, and posterior parts were stimulated at four to six sites across the longitudinal axis. The best site according to the pressure-volume loops was then selected for permanent pericardial pacemaker lead implantation.

\section{Biventricular Pacing}

The hemodynamic measurements during baseline and biventricular stimulation were performed with pacing in DDD mode at the lower rate of 80 beats/min with the atrioventricular interval set at $120 \mathrm{~ms}$ and, if applicable, a right to left ventricular delay of $0 \mathrm{~ms}$. 
TABLE 2. Hemodynamic data during baseline, biventricular pacing at the best site, and biventricular pacing at the worst site

\begin{tabular}{|c|c|c|c|c|c|}
\hline Variable & Baseline & Best site & $P$ value & Worst site & $P$ value \\
\hline Heart rate (beats/min) & $79 \pm 7$ & $80 \pm 7$ & .7 & $79 \pm 7$ & .2 \\
\hline Stroke volume (mL) & $51 \pm 6$ & $71 \pm 24$ & .01 & $55 \pm 10$ & .3 \\
\hline End-systolic volume (mL) & $154 \pm 72$ & $144 \pm 77$ & .04 & $149 \pm 66$ & .3 \\
\hline End-diastolic volume (mL) & $205 \pm 70$ & $215 \pm 90$ & .6 & $204 \pm 68$ & .5 \\
\hline $\begin{array}{l}\text { Maximal left ventricular pressure } \\
(\mathrm{mm} \mathrm{Hg})\end{array}$ & $79 \pm 15$ & $80 \pm 15$ & .4 & $78 \pm 15$ & .7 \\
\hline $\begin{array}{l}\text { End-diastolic left ventricular } \\
\text { pressure }(\mathrm{mm} \mathrm{Hg})\end{array}$ & $12 \pm 6$ & $13 \pm 6$ & .6 & $12 \pm 7$ & 6 \\
\hline $\mathrm{dP} / \mathrm{dt}_{\max }$ & $576 \pm 182$ & $689 \pm 258$ & .02 & $625 \pm 218$ & .12 \\
\hline $\mathrm{dP} / \mathrm{dt}_{\min }$ & $533 \pm 176$ & $571 \pm 215$ & .2 & $548 \pm 200$ & .9 \\
\hline Ejection fraction (\%) & $27 \pm 9$ & $35 \pm 10$ & .007 & $29 \pm 9$ & .2 \\
\hline Stroke work $(\mathrm{g} \cdot \mathrm{m})$ & $29 \pm 10$ & $48 \pm 10$ & .006 & $35 \pm 12$ & .2 \\
\hline$\tau(\mathrm{ms})$ & $113 \pm 36$ & $99 \pm 26$ & .11 & $105 \pm 33$ & .3 \\
\hline
\end{tabular}

$\tau$, Time constant of left ventricular pressure decline. $P$ values are versus baseline.

With these programming parameters, consistent stimulation of the right atrium and both ventricles could be achieved, with the paced atrioventricular interval shorter than spontaneous atrioventricular conduction in every case.

During the hemodynamic measurements, pacing was bipolar at the right atrial appendage and the apex. Various sites of the left ventricle were tested with both unipolar and bipolar stimulation; in the bipolar configuration, the left ventricular electrode was the cathode of the stimulation dipole and the right ventricular ring was the anode. The selection of the left ventricular segment for which stimulation resulted in the most hemodynamic improvement was followed by the selection of the pacing sites within that segment providing the best pacing and sensing characteristics.

\section{Statistical Analysis}

A nonparametric Wilcoxon signed rank test was performed to compare baseline versus biventricular pacing at the best site and baseline versus biventricular pacing at the worst site.

\section{Results}

The results, as summarized in Table 2, show that biventricular pacing had a significant acute hemodynamic effect. Relative to the baseline LBBB situation, biventricular pacing significantly increased stroke volume $(+39 \%, P=.01)$, $\mathrm{dP} / \mathrm{dt}_{\max }(+20 \%, P=.02)$, ejection fraction $(+30 \%, P=$ $.007)$, and stroke work $(+66 \%, P=.006)$ and reduced end-systolic volume $(-6 \%, P=.04)$. However, Table 2 also illustrates that this only held for biventricular pacing at an optimal site on the left ventricle. When the left ventricle was paced from the worst site, none of these parameters changed significantly.

For individual patients, this point is illustrated in Figure 1. With pacing at the best site, the vast majority of patients benefited from biventricular pacing. Figure 2 shows the corresponding pressure-volume loops. At the worst site, however, biventricular pacing was actually disadvantageous in some cases. Figure 3 shows examples of pressure-volume loops during biventricular pacing at the best and worst sites.
Pacing sites on the left ventricle were classified according to the grid on Figure 4. In most cases pacing at basal, midlateral, and apical segments was tested, and in some cases more anterior and posterior segments were added (Figure 4). The pacing sites on the left ventricle that had the best and worst effects on left ventricular function differed among patients (Figure 4).

\section{Discussion}

\section{Position of Left Ventricular Lead for CRT}

This study shows that position of the left ventricular lead is a primary determinant of the acute hemodynamic effect of biventricular pacing. If the best site was selected, acute and significant beneficial effects were observed with biventricular pacing. In contrast, with the worst site no significant effects were demonstrated, with actual deterioration of function in some cases (Figures 1 and 3). Although many reasons, including patient selection, may explain the high number of those without response to CRT $(30 \%)$ in the largest trial to date, ${ }^{1}$ suboptimal positioning of the left ventricular lead, as may occur during coronary sinus catheterization, may explain some of the failures. ${ }^{12}$

That the site of left ventricular stimulation is important has been reported before. Auricchio and colleagues ${ }^{7}$ showed that patients with an electrode in the midlateral region generally had the most improvement in $\mathrm{dP} / \mathrm{dt}_{\text {max }}$ with biventricular pacing. In that study, however, different sites were not compared in individual patients. Butter and associates ${ }^{8,9}$ did compare in individual patients an anterior with a midlateral left ventricular lead position, and they also concluded that the midlateral region was the best. On the basis of these results, the general approach at present is to place the left ventricular lead in the midlateral region. ${ }^{13}$

In contrast, Pappone and colleagues, ${ }^{11}$ in a study that compared midlateral and basal sites, concluded that the best pacing site varied among patients. More specifically, Ansa- 
BEST POSITION

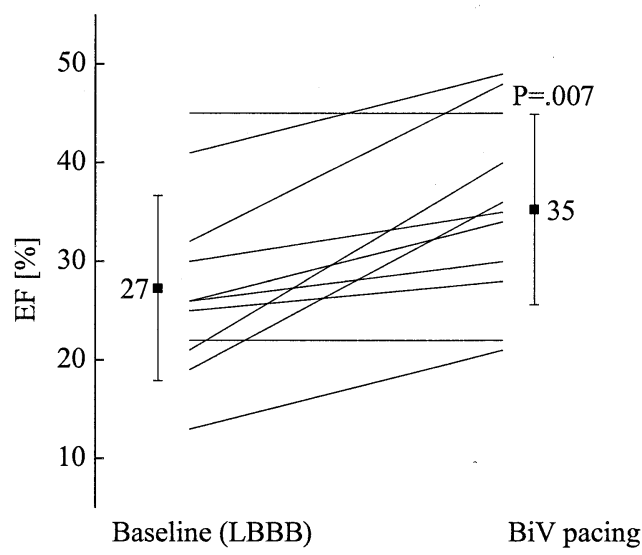

WORST POSITION
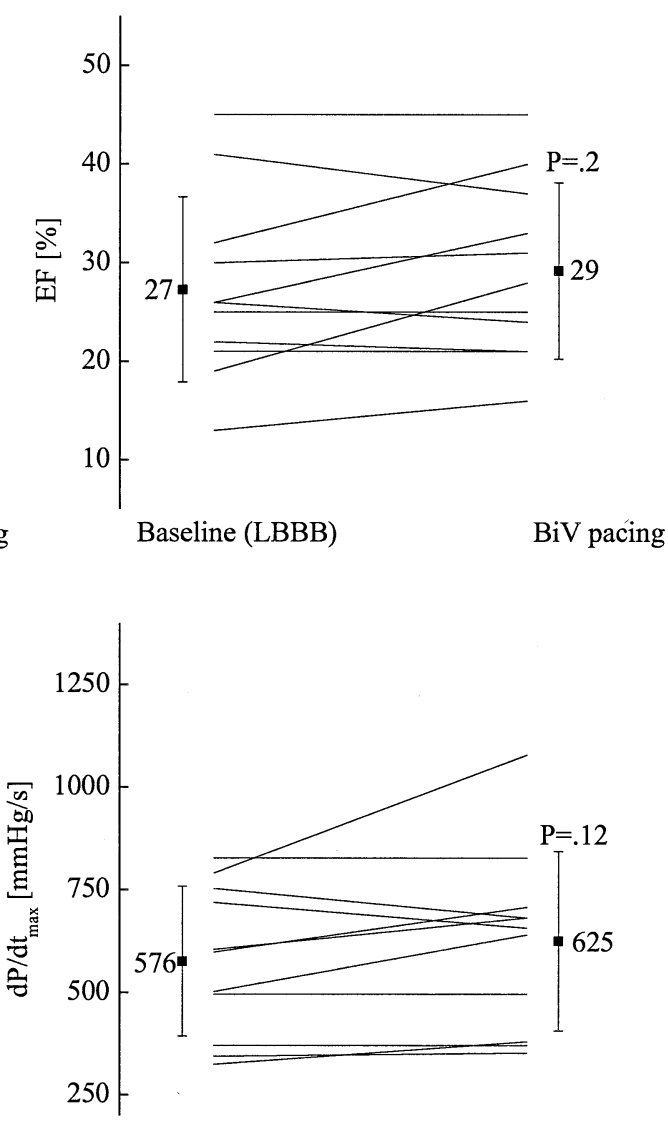

BiV pacing

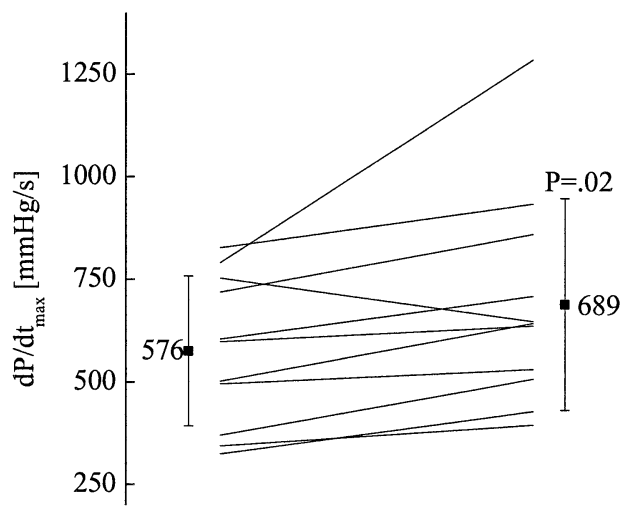

Baseline (LBBB)

BiV pacing

Baseline (LBBB)

BiV pacing
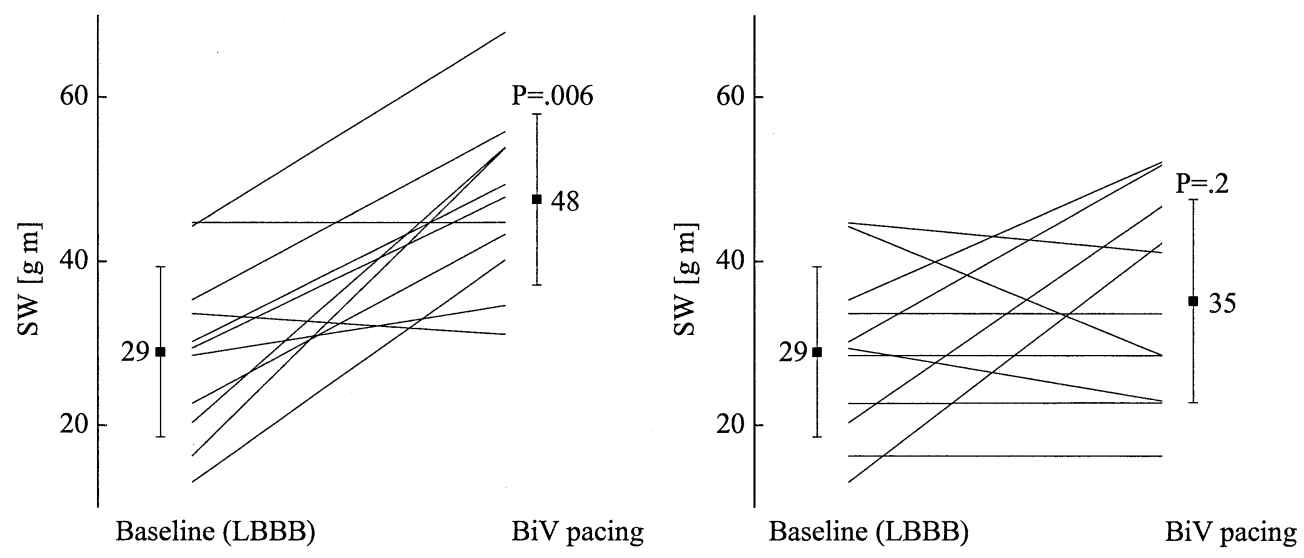

Figure 1. Comparison of LBBB versus biventricular (BiV) pacing at best and worst sites in 11 patients. EF, Ejection fraction; $S W$, stroke work.

lone and coworkers ${ }^{10}$ found that pacing at the site of last activation (according to echocardiography) reduced symptoms and ventricular dimensions most. This site of last activation could be anywhere on the left ventricular wall. ${ }^{10}$

A limitation of all these studies is that coronary sinus catheterization was used to place the left ventricular lead.
With coronary sinus catheterization, some segments of the left ventricle cannot be reached. In this study, with surgical lead placement, no such limitation existed and multiple positions could be tested and compared in the individual patients. Our results agree with the previously mentioned results of Ansalone and coworkers. ${ }^{10}$ The acute hemody- 


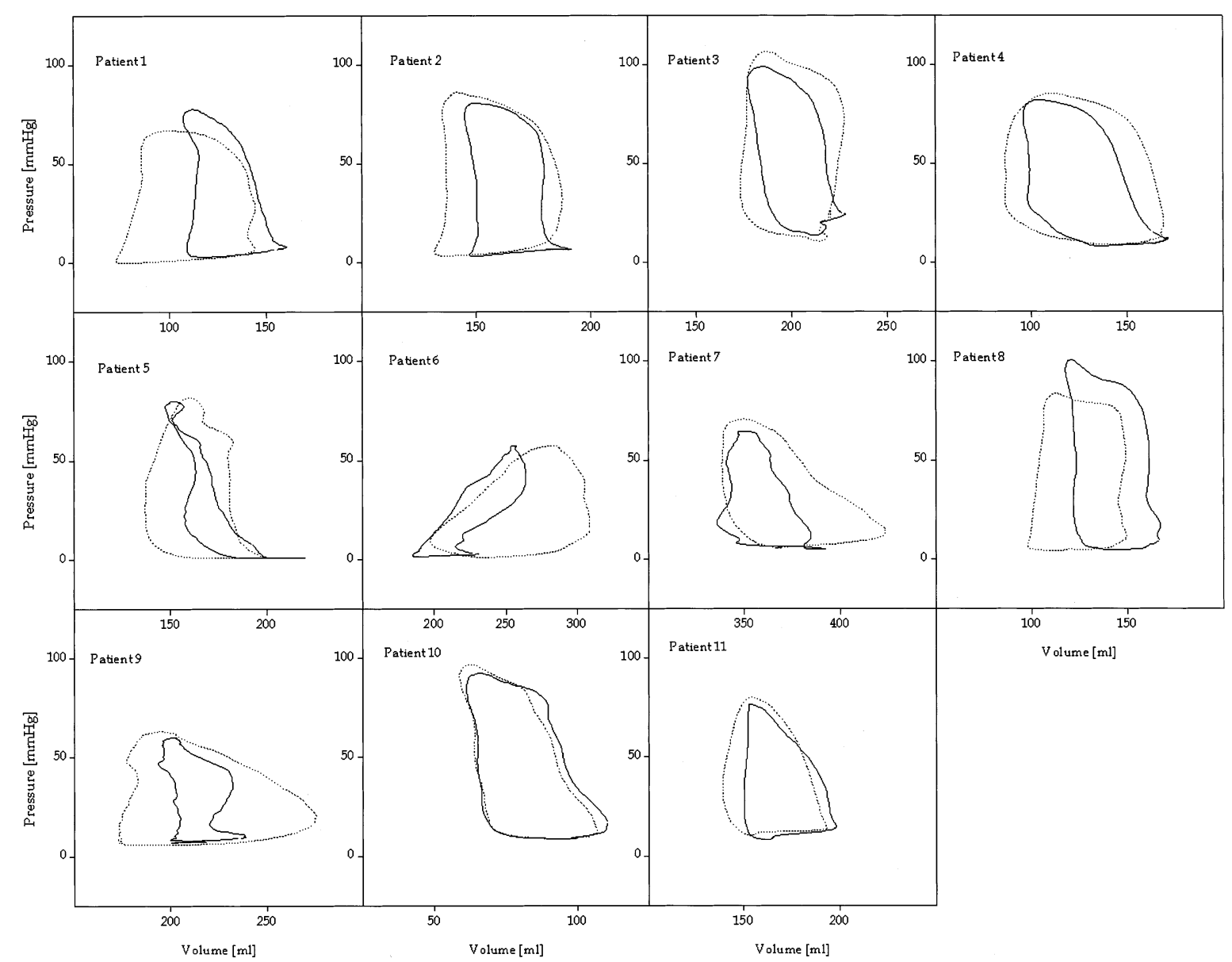

Figure 2. Pressure-volume loops for all patients during baseline (solid lines) and during biventricular pacing at best site (dotted lines).

namic effect of biventricular pacing varies with position, and the best and worst positions vary among patients (Figure 4).

\section{Pressure-Volume Loops to Guide Epicardial Lead Placement}

This study shows that pressure-volume loops are useful to select the optimal position in the individual patient. Pressure-volume loops give all the variables of Table 2 beatfor-beat and on-line, which makes the conductance technique the ideal tool during surgery because on-the-spot decisions can be made where to implant the electrode. Furthermore, because only relative changes are important to compare various positions, no calibration of the conductance catheter is necessary, which simplifies and shortens the procedure considerably.

It should be noted, however, that the design of the conductance catheter assumes that the left ventricle is a stack of cylinders that change in diameter. ${ }^{14}$ In a ventricle with LBBB, some regions (especially the septum) contract earlier than others, so this condition is clearly violated. Although this raises some doubts as to the correctness of the conductance-derived volume during LBBB, it has the beneficial effect that the catheter reacts strongly to more synchronous contraction, which is exactly the aim during CRT. This may explain the observation that stroke volume $(+39 \%)$, stroke work $(+66 \%)$, and to a lesser extent ejection fraction $(+30 \%)$ all reacted very strongly to biventricular pacing, whereas $\mathrm{dP} / \mathrm{dt}_{\max }$ was less sensitive $(+20 \%)$, although that parameter may be used when pressure-volume loops are unavailable.

In this study no attempt was made to derive changes in more load-independent indices of contractility, such as the slope of the end-systolic pressure-volume relation. The problem with these indices is that they require caval vein occlusion, which is difficult in a thoracoscopic setting and would therefore require additional catheterization with a balloon catheter. Furthermore, the determination of these indices requires off-line analysis, with careful selection of preload varied beats and regression of the end-systolic points. Such analysis would substantially lengthen and complicate the procedure, especially if many different positions 

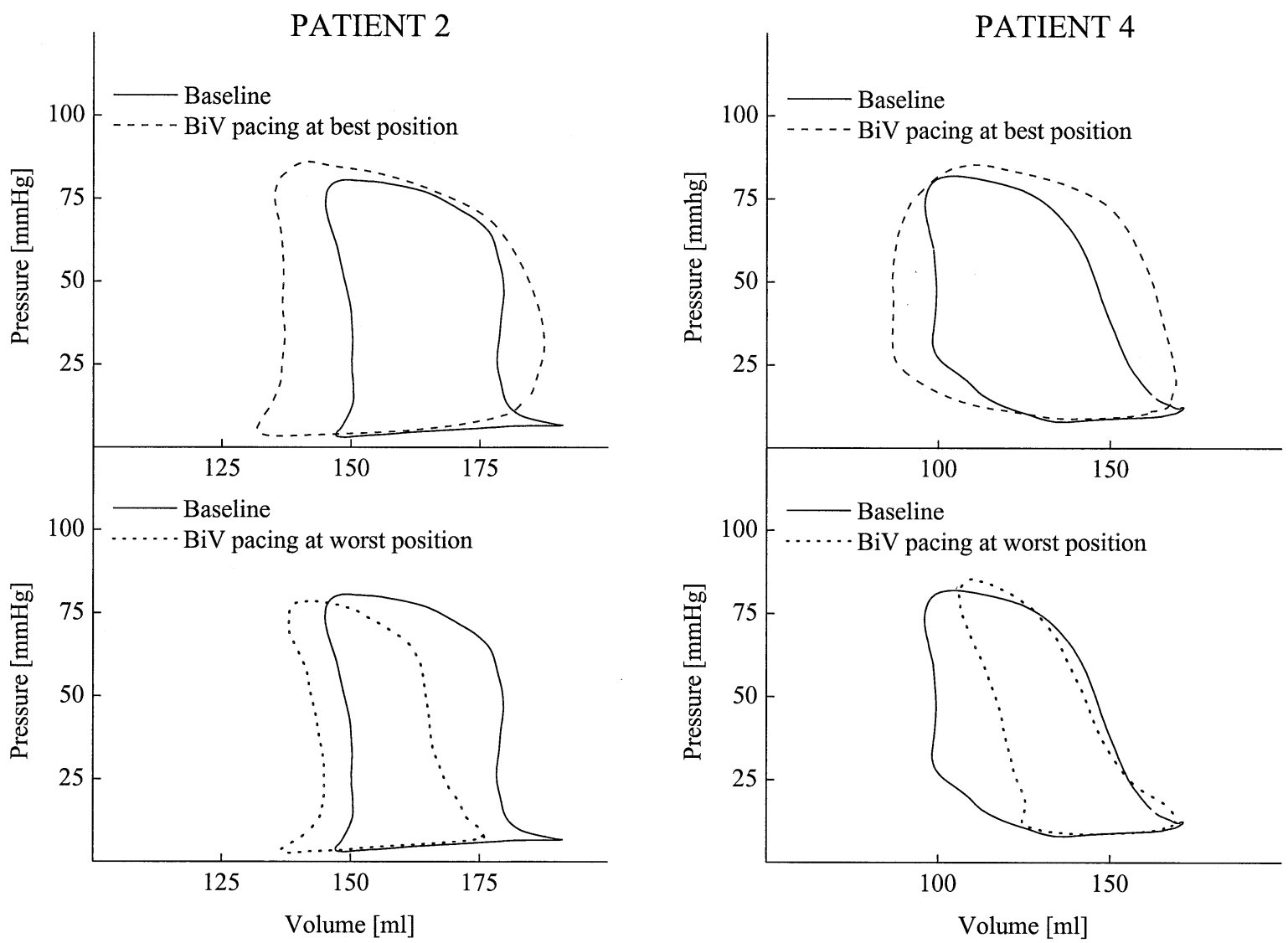

Figure 3. Pressure-volume loops in patients 2 and 4 during baseline (solid lines), during biventricular (BiV) pacing at best site (dashed lines), and during biventricular pacing at worst site (dotted lines).

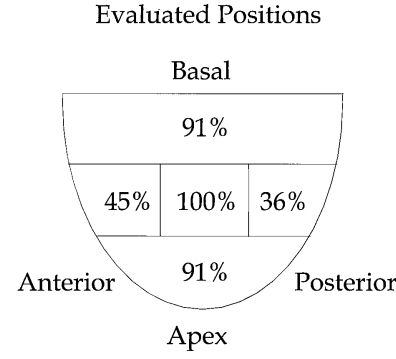

Best Position

Worst Position
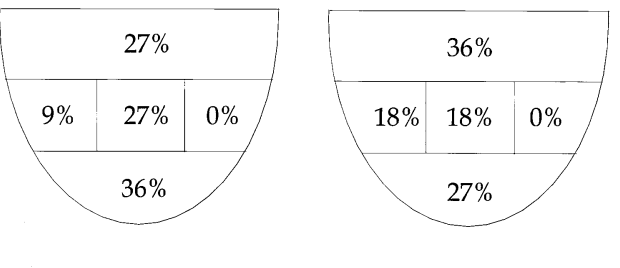

Figure 4. Left ventricular lead positions. Percentages of patients in which indicated sites were evaluated during procedure (left, multiple sites per patient); in which biventricular pacing at indicated site gave best acute hemodynamic effect (center), and in which biventricular pacing at indicated site gave worst acute hemodynamic effect (right).

(and maybe in future atrioventricular and right to left ventricular delay variations) are tested.

\section{Coronary Sinus Catheterization Versus Epicardial Lead Placement}

It has already been shown that epicardial lead placement has a shorter procedure time than does coronary sinus catheterization, ${ }^{4}$ and it can be expected that complications such as implantation failure and lead dislodgment will occur less frequently during surgery. Given the results of this study, one might hypothesize that placing the left ventricular lead by thoracoscopic surgery could offer advantages relative to the coronary sinus approach. A randomized clinical trial comparing outcomes of coronary sinus catheterization versus thoracoscopy should test this hypothesis. 


\section{Improvements to Surgical Placement of Permanent Electrode}

As shown in Figure 4, more posterior and anterior regions were not always evaluated in all patients in this study. The main reason was that it is not possible with current devices to place an electrode on these more remote regions during thoracoscopy. Implantation devices for permanent epicardial electrodes should therefore be improved.

\section{Study Limitations}

In this study only acute hemodynamic effects of biventricular pacing were used to select the best position. It is not known whether acute hemodynamic effects correlate with a reduction of symptoms in the long term. A study with a larger patient cohort with a longer follow-up is necessary to address this issue.

It is known that the atrioventricular delay modulates the acute hemodynamic effect of biventricular pacing. ${ }^{8,9}$ A limitation of this study is therefore that the atrioventricular delay was not varied at the different positions. No cases have been reported in which the atrioventricular delay could compensate for a bad position of the left ventricular lead, ${ }^{8,9}$ however, so the effect of position seems to be more prominent than that of the correct atrioventricular delay.

\section{Conclusion}

To optimize CRT with epicardial leads, mapping to determine the best pace site is a prerequisite. Pressure-volume loops offer real time guidance for targeting epicardial lead placement during minimally invasive surgery.

\section{References}

1. Abraham WT, Fisher WG, Smith AL, Delurgio DB, Leon AR, Loh E, et al. Cardiac resynchronization in chronic heart failure. $N$ Engl J Med. 2002;346:1845-53.

2. Cleland JG, Coletta AP, Nikitin N, Louis A, Clark A. Update of clinical trials from the American College of Cardiology 2003. EPHESUS, SPORTIF-III, ASCOT, COMPANION, UK-PACE and T-wave alternans. Eur J Heart Fail. 2003;5:391-8.

3. Bradley DJ, Bradley EA, Baughman KL, Berger RD, Calkins H, Goodman SN, et al. Cardiac resynchronization and death from progressive heart failure: a meta-analysis of randomized controlled trials. JAMA. 2003;289:730-40.

4. Izutani H, Quan KJ, Biblo LA, Gill IS. Biventricular pacing for congestive heart failure: early experience in surgical epicardial versus coronary sinus lead placement. Heart Surg Forum. 2002;6:E1-6.

5. Alonso C, Leclercq C, d'Allonnes FR, Pavin D, Victor F, Mabo P, et al. Six year experience of transvenous left ventricular lead implantation for permanent biventricular pacing in patients with advanced heart failure: technical aspects. Heart. 2001;86:405-10.

6. Valls-Bertault V, Mansourati J, Gilard M, Etienne Y, Munier S, Blanc JJ. Adverse events with transvenous left ventricular pacing in patients with severe heart failure: early experience from a single centre. $\mathrm{Eu}$ ropace. 2001;3:60-3.

7. Auricchio A, Klein H, Tockman B, Sack S, Stellbrink C, Neuzner J, et al. Transvenous biventricular pacing for heart failure: can the obstacles be overcome? Am J Cardiol. 1999;83:136D-42D.

8. Butter C, Auricchio A, Stellbrink C, et al. Should stimulation site be tailored in the individual heart failure patient? Am J Cardiol. 2000; 86:K144-K51.

9. Butter C, Auricchio A, Stellbrink C, Fleck E, Ding J, Yu Y, et al. Effect of resynchronization therapy stimulation site on the systolic function of heart failure patients. Circulation. 2001;104:3026-9.

10. Ansalone G, Giannantoni P, Ricci R, Trambaiolo P, Fedele F, Santini M. Doppler myocardial imaging to evaluate the effectiveness of pacing sites in patients receiving biventricular pacing. J Am Coll Cardiol. 2002;39:489-99.

11. Pappone C, Rosanio S, Oreto G, Tocchi M, Gulletta S, Salvati A, et al. Cardiac pacing in heart failure patients with left bundle branch block: impact of pacing site for optimizing left ventricular resynchronization. Ital Heart J. 2000;1:464-9.

12. Ansalone G, Giannantoni P, Ricci R, Trambaiolo P, Fedele F, Santini M. Biventricular pacing in heart failure: back to basics in the pathophysiology of left bundle branch block to reduce the number of nonresponders. Am J Cardiol. 2003;91:55F-61F.

13. Purerfellner H, Nesser HJ, Winter S, et al. Transvenous left ventricular lead implantation with the EASYTRAK lead system: the European experience. Am J Cardiol. 2000;86:K157-K64.

14. Baan J, van der Velde ET, de Bruin HG, Smeenk GJ, Koops J, van Dijk AD, et al. Continuous measurement of left ventricular volume in animals and humans by conductance catheter. Circulation. 1984;70: 812-23.

\section{Bound volumes available to subscribers}

Bound volumes of The Journal of Thoracic and Cardiovascular Surgery are available to subscribers (only) for the 2004 issues from the Publisher, at a cost of $\$ 134.00$ for domestic, $\$ 165.85$ for Canadian, and $\$ 155.00$ for international subscribers for Vol 127 (January-June) and Vol 128 (July-December). Shipping charges are included. Each bound volume contains a subject and author index and all advertising is removed. The binding is durable buckram with the Journal name, volume number, and year stamped in gold on the spine. Payment must accompany all orders. Contact Elsevier Inc., Subscription Customer Service, 6277 Sea Harbor Dr, Orlando, FL 32887, USA; phone 800-654-2452 or 407-345-4000.

Subscriptions must be in force to qualify. Bound volumes are not available in place of a regular Journal subscription. 